\title{
PRILAGOĐENA KLASIČNA REGULACIJA NAPONA U AKTIVNIM DISTRIBUTIVNIM MREŽAMA
}

\section{ADAPTED CLASSIC VOLTAGE REGULATION IN ACTIVE DISTRIBUTION NETWORKS}

\author{
Slađan Aćimović, Fakultet tehničkih nauka, Novi Sad
}

\begin{abstract}
Oblast - ELEKTROTEHNIKA I RAČUNARSTVO
Kratak sadržaj - U ovom radu predstavljen je jednostavan matematički model kojim se uzima u obzir uticaj distributivnih generatora na regulaciju napona $u$ distributivnim mrežama. Primenom modela je omogućeno da se klasična regulacija napona prilagodi aktivnim distributivnim mrežama.
\end{abstract}

Ključne reči: Distributivni generator, Regulacija napona, Automatski regulator napona

Abstract - In this paper, simple mathematical model correcting the impact of distributed generation on voltage regulation in distribution networks is presented. Using this model, classical voltage regulation is adapted to active distribution networks.

Keywords: Distributed generation, Voltage regulation, Automatic voltage regulator

\section{UVOD}

Porast potreba za energijom u svetu mora biti praćen izgradnjom novih elektrana. Pored velikih elektrana koje se priključuju na prenosnu mrežu, u novije vreme sve više se koriste obnovljivi izvori energije i sve više se grade distributivni generatori (DG) koji se priključuju direktno na distributivnu mrežu (DM). Jedna od ključnih prednosti elektrana na obnovljive izvore električne energije je to da se one uglavnom nalaze na distributivnim područjima, pa su gubici mnogo manji [1]. Izvori električne energije su neiscrpni, emisija štetnih gasova je mala, pa su i ovo razlozi koji su doveli do povećanog broja instalacija elektrana na ove izvore [1].

Pored navedenih prednosti, postoje i određeni nedostaci u ovakvom vidu proizvodnje električne energije. Izgradnja DG dovodi do promena strukture DM. Mreže koje su ranije bile radijalne i napajale se iz jednog izvora, sada postaju mreže sa petljama, te se energija potrošačima sada isporučuje i iz samih DG.

Dakle, usled promene strukture mreže javljaju se i određeni negativni efekti priključenja DG. Negativni efekti mogu se prevazići ugradnjom novih vidova zaštite, novih elemenata mreže, promenom preseka vodova i slično. Međutim sve to ima svoju cenu i dobro bi bilo kada bi se uz male promene postojeći kapaciteti mogli iskoristiti što je više moguće.

\section{NAPOMENA:}

Ovaj rad proistekao je iz master rada čiji mentor je bio dr Goran Švenda, red.prof.
U ovom radu razmatra se uticaj DG na regulaciju napona u DM. U radu je predstavljeno jednostavno i jeftino rešenje na osnovu koga se koriguje lažna slika koja se javlja u vidu struje kroz transformator, koja ne odgovara struji potrošnje. Za potrebe simulacija razvijen je program u programskom jeziku $\mathbf{C}++$. Koristi se proračun tokova snaga zasnovan na algoritmu sumiranja struja [2].

\section{MATEMATIČKI MODEL}

Uticaj DG na regulaciju napona ogleda se u stvaranju lažne slike potrošnje. U okviru tzv. klasične regulacije napona regulacioni transformator (RTr) na osnovu struje na njegovom sekundaru, koristeći automatski regulator napona (ARN) određuje optimalnu vrednost napona, te eventualno menja prenosni odnos kako bi postigao napon blizak optimalnom. Struja sekundara RTr je u slučaju klasične radijalne $\mathrm{DM} u$ stvari ekvivalentna struja potrošnje. Priključenjem DG menjaju se tokovi snaga u mreži, te struja kroz sekundar RTr nije stvarna struja potrošnje. Posledica toga je da na osnovu merenja samo modula struje sekundara nije moguće proceniti prirodu i vrednost opterećenja, a samim tim ni optimalnu vrednost napona, odnosno odgovarajuću poziciju regulacione sklopke. U ovom radu predstavljeno je rešenje ovog problema, koje se zasniva na tome da se ARN-u ne prosleđuje struja sekundara, nego procenjena struja potrošnje. Ta procena se realizuje na osnovu izmerenih vrednosti modula napona na sekundaru RTr, modula struje na sekundaru RTr i modula struje na početku izvoda sa DG (pri čemu je vrednost faktora snage DG poznata).

U svrhu izvođenja matematičkog modela, posmatra se jednostavna DM na slici 1. DM se sastoji iz RTr, izvoda sa DG i izvoda sa potrošnjom.

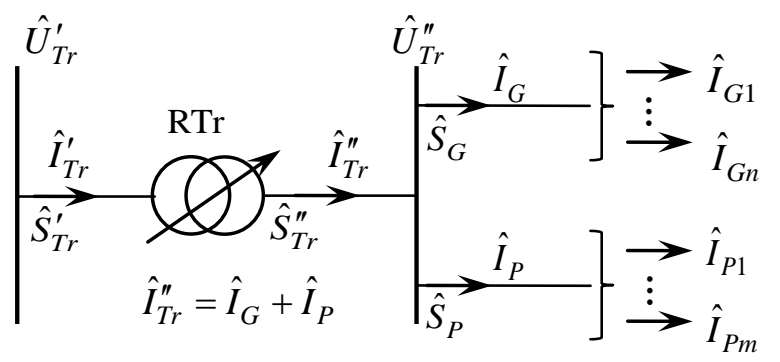

Slika 1 - Jednostavna DM

$\mathrm{Na}$ početku je potrebno proceniti režim izvoda sa DG. Ekvivalentna šema izvoda prikazana je na slici 2. Na osnovu unapred definisane vrednosti faktora snage DG 
$\cos \varphi_{G}^{\prime} \approx 1$ i izmerenih vrednosti modula struje $I_{G}$ i napona $U_{T r}^{\prime \prime}$ na početku izvoda, može se proceniti kompleksna struja $\hat{I}_{G}$. Fazori struja i napona razmatranog izvoda prikazani su na slici 3. Sa $\alpha$ je označen ugao između struja na kraju i na početku izvoda sa DG.

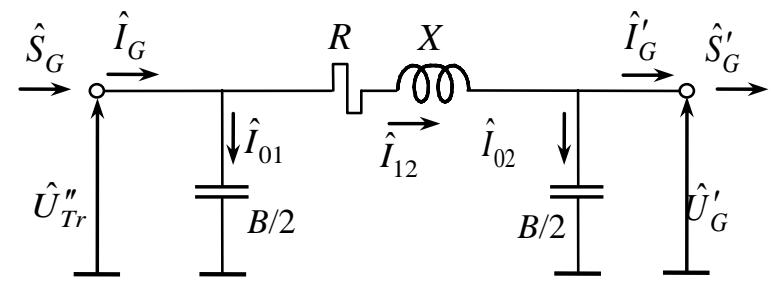

Slika 2 - Izvod sa $D G$

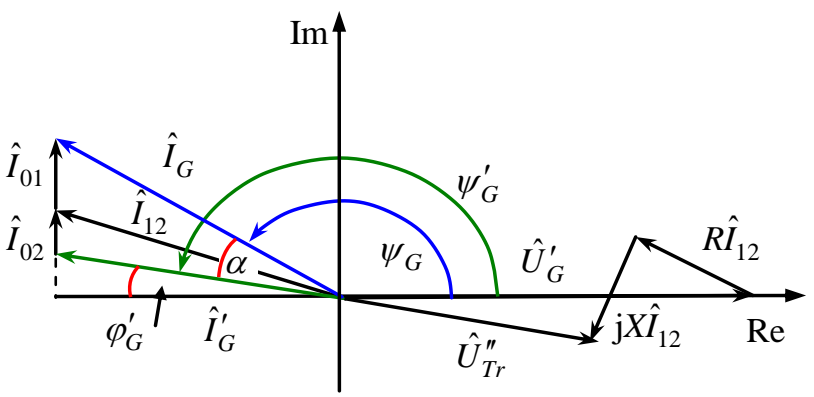

Slika 3 - Vektorski dijagram struja i napona izvoda sa DG

Na osnovu slike 3 može se izvesti izraz za proračun vrednosti ugla $\alpha$. U tu svrhu, potrebno je struju na kraju izvoda sa DG izraziti preko aktivne i reaktivne snage DG, pa potom izraziti struju na početku ovog izvoda preko struje na kraju izvoda i otočnih struja. Pritom, potrebno je uvesti aproksimacija da je napon na kraju izvoda sa DG jednak naponu na njegovom početku:

$$
\hat{U}_{T r}^{\prime \prime} \approx \hat{U}_{G}^{\prime}=U_{T r}^{\prime \prime} \angle 0^{\circ} \text {. }
$$

Izjednačavanjem realnih delova struja $\hat{I}_{G}$ i $\hat{I}_{G}^{\prime}$ i otočnih struja sa početka i kraja voda (posledica izraza (1), slika 3 ), primenom kosinusne teoreme na trougao sa stranicama $I_{G}, I_{G}^{\prime}$ i $I_{01}+I_{02}$ može da se proceni vrednost ugla:

$$
\alpha=\arcsin \frac{B \cdot U_{T r}^{\prime \prime}}{I_{G}} \cos \varphi_{G}^{\prime},
$$

gde je $B$ ukupna otočna susceptansa izvoda sa DG.

Konačno, na osnovu procenjene vrednosti ugla $\alpha$ i izmerene vrednosti modula, struja na početku izvoda sa DG ima sledeći kompleksni oblik:

$$
\hat{I}_{G}=-I_{G} \cos \left(\varphi_{G}^{\prime}+\alpha\right)+\mathrm{j} \cdot I_{G} \sin \left(\varphi_{G}^{\prime}+\alpha\right) .
$$

\subsection{Korekcija ugla napona generatora}

Aproksimacija koja se pravi izrazom (1) u zavisnosti od režima, može da prouzrokuje značajnu grešku pri proceni fazora struje potrošnje. U nastavku je pokazan postupak za korekciju greške koja je navedenom aproksimacijom načinjena. $U$ tu svrhu, na slici 3 prikazan je novi vektorski dijagram struja i napona izvoda sa DG. Na ovoj slici usvojeno je da je fazor napon na početku izvoda sa DG referentni fazor, a da fazor napona na kraju izvoda prednjači za ugao $\theta$.

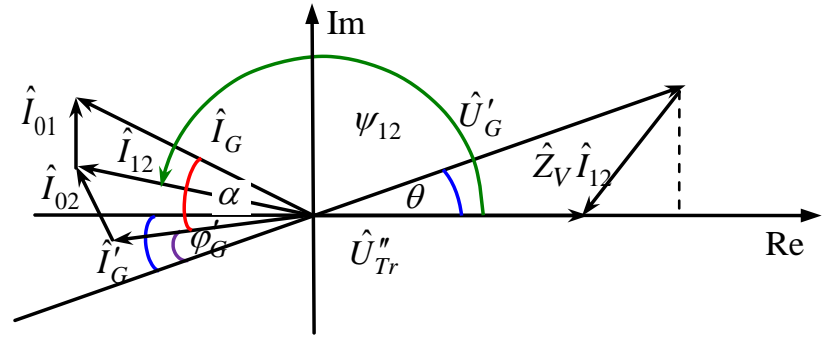

Slika 4 - Vektorski dijagram struja i napona izvoda sa DG sa uvaženim uglom $\theta$

Na osnovu dijagrama sa slike 4 sledi:

$$
\theta=\arcsin \left(\frac{\left|\operatorname{Im}\left\{\hat{Z}_{V} \cdot \hat{I}_{12}\right\}\right|}{U_{G}^{\prime}}\right),
$$

gde je :

$\hat{Z}_{V} \quad$ - kompleksna impedansa izvoda sa DG,

$\hat{I}_{12}-$ struja duž izvoda sa DG.

Pretpostavlja se da fazor struje $\hat{I}_{12}$ približno deli ugao $\alpha$ na pola, zatim da je moduo napona na kraju izvoda sa DG $U_{G}^{\prime}$ približno jednak modulu napona na sekundaru $\mathrm{RTr}$ $U_{T r}^{\prime \prime}$, te da je $I_{12} \approx I_{G}$. Imaginarni deo kompleksnog pada napona na izvodu sa DG je negativan (slika 4), pa se umesto apsolutne vrednosti u izrazu (4) uzima negativna vrednost. Kompleksna impedansa izvoda definisana je na osnovu poznavanja rezistanse i reaktanse izvoda. Izraz (4) na kraju se može zapisati kao:

$$
\theta=\operatorname{arctg}\left[\frac{-A \sin B}{1+A \cos B}\right],
$$

gde je :

$$
\begin{gathered}
A=\frac{Z_{V} \cdot I_{G}}{U_{T r}^{\prime \prime}}, \\
B=\varphi_{V}+180^{\circ}-\frac{\alpha}{2}-\varphi_{G}^{\prime},
\end{gathered}
$$

pri čemu je $\varphi_{V}$ ugao kompleksne impedanse izvoda $\hat{Z}_{V}$.

Konačno, struja na početku izvoda sa DG ima sledeću kompleksnu vrednost:

$$
\hat{I}_{G}=-I_{G} \cos \left(\varphi_{G}^{\prime}+\alpha-\theta\right)+\mathrm{j} \cdot I_{G} \sin \left(\varphi_{G}^{\prime}+\alpha-\theta\right) .
$$

\subsection{Procena režima transformatora}

Za procenu ukupne struje potrošnje, potrebno je osim procene struje na početku izvoda sa DG proceniti i kompleksnu vrednost struje na sekundaru RTr (poznata je samo vrednost modula te struje). Pad napona na RTr, odnosno razlika modula napona primara svedenog na sekundar i napona sekundara je približno jednaka realnom delu kompleksnog pada napona (promene napona [4]):

$$
\frac{U_{T r}^{\prime}}{m_{12}(t)}-U_{T r}^{\prime \prime}=d U_{T r}^{\prime \prime} \approx \operatorname{Re}\left\{\Delta \hat{U}_{T r}^{\prime \prime}\right\} .
$$

Iz prethodnog izraza sledi:

$$
d U_{T r}^{\prime \prime}=X_{k}^{\prime \prime} \cdot \hat{I}_{T r}^{\prime \prime} \cdot \cos \left(90^{\circ}+\psi_{T r}^{\prime \prime}\right),
$$


gde je:

$X_{k}^{\prime \prime} \quad$ reaktansa kratkog spoja $\mathrm{R} \operatorname{Tr}$ (svedena na sekundar,

$I_{T r}^{\prime \prime} \quad$ moduo struje kroz sekundar RTr,

$\psi_{T r}^{\prime \prime} \quad$ ugao struje kroz sekundar RTr.

Izraz za procenu vrednosti ugao struje na sekundaru RTr:

$$
\psi_{T r}^{\prime \prime}=-90^{\circ} \pm \arccos \left[\frac{d U_{T r}^{\prime \prime}}{X_{k}^{\prime \prime} \cdot I_{T r}^{\prime \prime}}\right]
$$

Predznak drugog dela izraza definisan je sa smerom toka aktivne snage i vrednošću pada napona na RTr (odnosno toka reaktivne snage) [3]. Pregled mogućih slučajeva dat je u tabeli 1 .

Tabela 1 - Četiri moguća rešenja za ugao $\psi_{T r}^{\prime \prime}$

\begin{tabular}{|c|c|c|}
\hline$d U_{T r}^{\prime \prime}$ & $P$ & Znak u izrazu za $\psi_{T r}^{\prime \prime}$ \\
\hline$>0$ & $>0$ & + \\
\hline$>0$ & $<0$ & - \\
\hline$<0$ & $>0$ & + \\
\hline$<0$ & $<0$ & - \\
\hline
\end{tabular}

\subsection{Procena struje potrošnje}

Konačno, procenjena vrednost modula struje ukupne potrošnje, modul struje koju treba proslediti u ARN jeste:

$$
\begin{aligned}
& I_{A R N}=\left\{\left[I_{T r}^{\prime \prime} \cos \psi_{T r}^{\prime \prime}+I_{G} \cos \left(\varphi_{G}^{\prime}+\alpha\right)\right]^{2}\right. \\
& \left.+\left[I_{T r}^{\prime \prime} \sin \psi_{T r}^{\prime \prime}-I_{G} \sin \left(\varphi_{G}^{\prime}+\alpha\right)\right]^{2}\right\}^{1 / 2} .
\end{aligned}
$$

Ukoliko se izvrši i dodatna korekcija, u vidu procene ugla $\theta$, na osnovu izraza (5), prethodni izraz glasi:

$$
\begin{aligned}
I_{A R N} & =\left\{\left[I_{T r}^{\prime \prime} \cos \psi_{T r}^{\prime \prime}+I_{G} \cos \left(\varphi_{G}^{\prime}+\alpha-\theta\right)\right]^{2}\right. \\
& \left.+\left[I_{T r}^{\prime \prime} \sin \psi_{T r}^{\prime \prime}-I_{G} \sin \left(\varphi_{G}^{\prime}+\alpha-\theta\right)\right]^{2}\right\}^{1 / 2}
\end{aligned}
$$

\section{VERIFIKACIJA MATEMATIČKOG MODELA}

Verifikacija mogućnosti prikazanog modela za procenu modula struje potrošnje u DM sa DG, izvršena je na primeru jednostavne test mreža prikazana na slici 5 . U tu svrhu razvijen je program u programskom jeziku $\mathbf{C}++$.

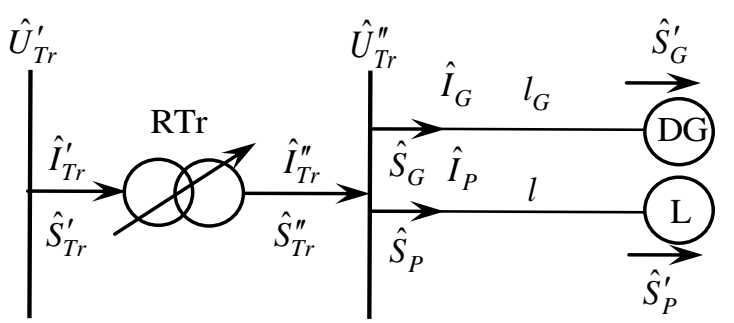

Slika 5. Test mreža

Tablični podaci RTr dati su u tabeli 2, a podaci o DM u tabeli 3.

Tabela 2 - Tablični podaci $\mathrm{RTr}$

\begin{tabular}{|l|l|}
\hline Prenosni odnos & $(110 \pm 10 \times 1.25 \% / 20) \mathrm{kV} / \mathrm{kV}$ \\
\hline Nominalna snaga & $63 \mathrm{MVA}$ \\
\hline Napon kr. spoja & $5 \%$ \\
\hline Aktuelna pozicija & 0 \\
\hline
\end{tabular}

Tabela 3 - Podaci o DM

\begin{tabular}{|c|c|c|c|}
\hline$l_{G}[\mathrm{~km}]$ & $l[\mathrm{~km}]$ & $Z_{G}[\Omega / \mathrm{km}]$ & $Z_{P}[\Omega / \mathrm{km}]$ \\
\hline 10 & 10 & $0.420+\mathrm{j} 0.390$ & $0.410+\mathrm{j} 0.360$ \\
\hline
\end{tabular}

U tabeli 4 prikazane su vrednosti od interesa, za tri karakteristična režima razmatrane DM: 1) DG ne radi, 2) DG injektira 5 MW i 3) DG injektira 10 MW. Sa boldom su naglašene vrednosti koje se koriste kao merenja (vrednosti potrebne za proračune).

Tabela 4 - Rezultati proračuna tokova snaga

\begin{tabular}{|c|c|c|c|}
\hline & Režim 1 & Režim 2 & Režim 3 \\
\hline$S_{P}^{\prime}$ & $5.0-\mathrm{j} 2.5$ & $5.0-\mathrm{j} 2.5$ & $5.0-\mathrm{j} 2.5$ \\
\hline$S_{G}^{\prime}$ & $0.0-\mathrm{j} 0.0$ & $5.0-\mathrm{j} 0.0$ & $10.0-\mathrm{j} 0.0$ \\
\hline $\cos \varphi_{G}^{\prime}$ & $\mathbf{1 . 0}$ & $\mathbf{1 . 0}$ & $\mathbf{1 . 0}$ \\
\hline$\hat{I}_{G}[\mathrm{~A}]$ & $\mathbf{1 1 . 5} \angle 89.7^{\circ}$ & $\mathbf{1 3 7 . 8} \angle 177.6^{\circ}$ & $\mathbf{2 6 4 . 1} \angle-177.4^{\circ}$ \\
\hline$\hat{I}_{P}[\mathrm{~A}]$ & $170.7 \angle-24.8^{\circ}$ & $170.7 \angle-24.6^{\circ}$ & $170.8 \angle-24.4^{\circ}$ \\
\hline$\hat{I}_{T r}^{\prime \prime}[\mathrm{A}]$ & $\mathbf{1 6 6 . 2} \angle-21.2^{\circ}$ & $\mathbf{6 7 . 6} \angle-75.0^{\circ}$ & $\mathbf{1 3 6 . 0} \angle-142.7^{\circ}$ \\
\hline$\hat{U}_{T r}^{\prime}[\mathrm{kV}]$ & $\mathbf{6 3 . 5} \angle 0.0^{\circ}$ & $\mathbf{6 3 . 5} \angle 0.0^{\circ}$ & $\mathbf{6 3 . 5} \angle 0.0^{\circ}$ \\
\hline$\hat{U}_{T r}^{\prime \prime}[\mathrm{kV}]$ & $\mathbf{1 1 . 5} \angle-0.3^{\circ}$ & $\mathbf{1 1 . 5} \angle-0.0^{\circ}$ & $\mathbf{1 1 . 5} \angle 0.2^{\circ}$ \\
\hline
\end{tabular}

U tabeli 5 prikazane su vrednosti karakterističnih veličina, koje su potrebne za procenu vrednosti struje potrošnje, dobijene na osnovu proračuna tokova snaga. Procena tih vrednosti, samo na osnovu izmerenih vrednosti (vrednosti u tabeli 4 naznačene sa boldom), primenom postupka koji je prikazan u glavi 2, prikazane su u tabeli 6. Procena je izvršena sa i bez korekcije ugla $\theta$.

Tabela 5. Vrednosti karakterističnih veličina i struje potrošnje (tokovi snaga)

\begin{tabular}{|c|r|r|r|}
\hline & Režim 1 & \multicolumn{1}{|c|}{ Režim 2} & \multicolumn{1}{c|}{ Režim 3 } \\
\hline$\alpha\left[^{\circ}\right]$ & 89.70 & 4.92 & 2.61 \\
\hline $\operatorname{Re}\left\{\Delta \hat{U}_{T r}^{\prime \prime}\right\}[\mathrm{V}]$ & 19.09 & 20.73 & 26.16 \\
\hline$\psi_{T r}^{\prime \prime}\left[^{\circ}\right]$ & -21.20 & -74.97 & -142.7 \\
\hline$\theta\left[^{\circ}\right]$ & -0.12 & 2.54 & 5.00 \\
\hline$I_{P}[\mathrm{~A}]$ & 170.69 & 170.73 & 170.84 \\
\hline
\end{tabular}

Tabela 6. Vrednosti karakterističnih veličina i struje potrošnje (matematički model)

\begin{tabular}{|c|r|r|r|}
\hline & Režim 1 & Režim 2 & Režim 3 \\
\hline$\alpha\left[^{\circ}\right]$ & 87.47 & 4.80 & 2.50 \\
\hline$d U_{T r}^{\prime \prime}[\mathrm{V}]$ & 18.98 & 20.73 & 26.10 \\
\hline$\psi_{T r}^{\prime \prime}\left[^{\circ}\right]$ & -21.08 & -74.95 & -142.81 \\
\hline$\theta\left[^{\circ}\right]$ & -0.01 & 2.42 & 4.54 \\
\hline$I_{A R N}$ bez $\theta[\mathrm{A}]$ & 171.19 & 172.89 & 181.53 \\
\hline$I_{A R N}$ sa $\theta[\mathrm{A}]$ & 171.19 & 170.71 & 171.74 \\
\hline
\end{tabular}

Poredeći tačne vrednosti, koje su prikazane u tabeli 5 sa procenjenim, izračunatim vrednostima, koje su prikazane u tabeli 6 , može se uočiti sledeće:

- izračunate vrednosti svih veličina veoma su bliske tačnim vrednostima;

- ako se procena modula struje potrošnje uradi sa 
korekcijom ugla $\theta$ na kraju izvoda sa DG, primenom izraza (12), dobija se izuzetno dobra vrednost (veoma bliska izračunatoj vrednosti struje potrošnje, za sva tri režima);

- ako se procena uradi bez korekcije ugla $\theta$, primenom izraza (11), greška u proceni struje potrošnje raste sa porastom snage DG.

Na slici 6a prikazana su odstupanja procenjene vrednosti modula struje potrošnje, u odnosu na tačnu vrednost (proračun tokova snaga, crna linija). Procene su urađene bez korekcije ugla $\theta$, crvena linija, i sa korekcijom ugla, plava linija. Na slici $6 \mathrm{~b}$ je prikazana greška u procentima, u odnosu na stvarnu vrednost struje potrošnje. Analiza je urađena za jednostavnu DM, sa konstantnom potrošnjom 5.0-j2.5 MVA i različitom proizvodnjom aktivne snage DG, od 0 do $10 \mathrm{MW}$, sa korakom 0.01 MW.
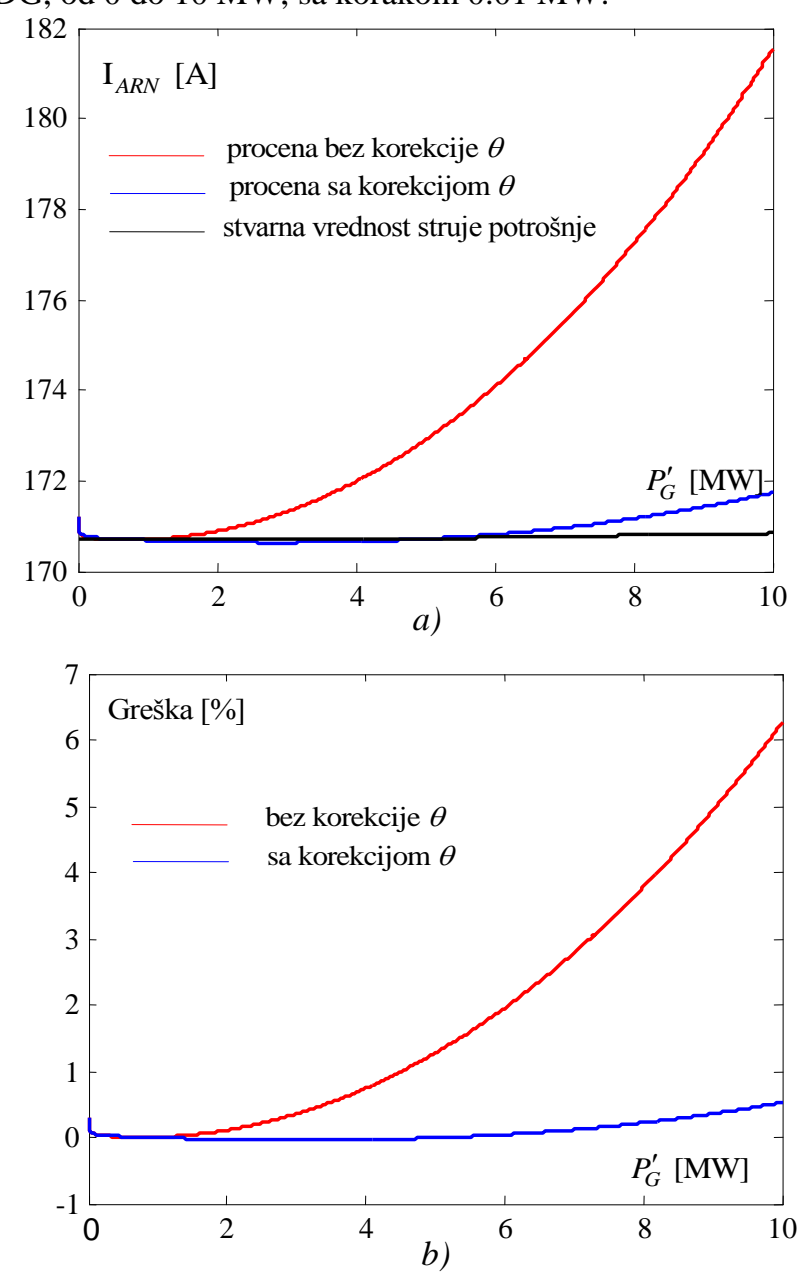

Slika 6. a) Procena vrednosti modula struje potrošnje, b) Greške u odnosu na stvarnu vrednost

Može se uočiti da se za male vrednosti aktivne snage DG dovoljno tačne vrednosti dobijaju primenom oba modela, sa i bez korekcije ugla $\theta$. Sa porastom vrednosti aktivne snage DG raste greška u proceni modela bez korekcije ugla $\theta$, ali ne i greška modela sa korekcijom ugla $\theta$. Na slici 6 b može se uočiti da je prim malom uticaju DG, greška koja se pravi primenom modela bez korekcije ugla $\theta$, praktično zanemarivo mala.

\section{ZAKLJUČAK}

U skladu sa savremenim trendovima u elektroenergetici, $\mathrm{u}$ mnogim državama sveta sve više se koriste obnovljivi izvori električne energije i izgrađuje se sve veći broj distributivnih generatora. U skladu sa tim, struktura distributivnih mreža se menja, pasivne radijalne mreže transformišu se u aktivne mreže sa petljama. Kao posledica toga, distributivna preduzeća će morati da se prilagode ili $\mathrm{u}$ potpunosti promene klasične principe svoga delovanja. Ugradnjom distributivnih generatora struja sekundara transformatora više ne odgovara struji potrošnje, te $u$ skladu sa tim ARN donosi odluke na osnovu pogrešnih informacija - lažne slike o opterećenju. U okviru ovog rada predloženo je jednostavno rešenje ovog problema. Rešenje se sastoji iz modifikacije postojećeg sistema klasične regulacije napona, gde se struja na sekundaru koriguje koristeći postojeća SCADA merenja. Na ovaj način izbegnuta je skupa nadogradnja i ulaganje u distributivne mreže. U radu su razmatrana dva načina za procenu struje potrošnje: bez korekcije ugla na kraju izvoda sa generatorom (ugao $\theta$ ) i sa navedenom korekcijom. Pokazano je da se za različite vrednosti snage generatora postiže prilično dobra procena struje potrošnje u oba slučaja, s tim da je za veće snage generatora ugao $\theta$ značajniji, pa se bez njegove korekcije dobija nešto veća greška u odnosu na stvarnu vrednost struje potrošnje. Odgovarajućom procenom struje potrošnje, automatski regulator napona će moći da odredi optimalnu vrednost napona na sekundaru transformatora, odnosno odgovarajuću poziciju regulacione sklopke.

\section{LITERATURA}

[1] F.A.Viawan: Voltage Control and Voltage Stability of Power Distribution Systems in the Presence of Distributed Generation, PhD Thessis, Chalmers University of technology Göteborg, Sweden, 2008.

[2] G.Švenda: Specijalizovani softveri u elektroenergetici, predavanja na FTN, Novi Sad, 2018.

[3] G.Švenda, Z.Simendić: Advanced voltage control in distribution network with $D G$, International Conference Energy and Ecology Industry, October, Belgrade, 2018.

[4] V.Strezoski: Osnovi elektroenergetike, Fakultet tehničkih nauka, Novi Sad, 2014.

\section{Kratka biografija:}

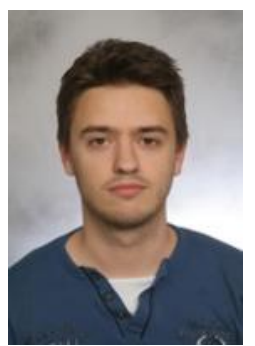

Slađan Aćimović rođen je u Trebinju 1994. godine. Diplomski rad na Fakultetu tehničkih nauka u Novom Sadu odbranio je 2017. godine u oblasti Elektrotehnika i računarstvo, smer Elektroenergetski sistemi. Iste godine upisuje master studije na istom smeru. 